\title{
Seasonal aspects of weight-for-age in young children in Zimbabwe
}

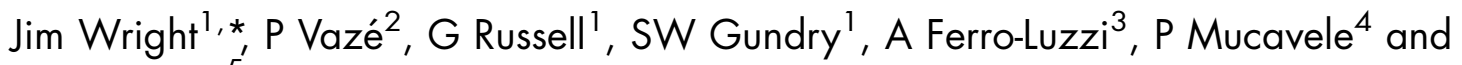 \\ J Nyatsanza ${ }^{5}$ \\ ${ }^{1}$ Institute of Ecology and Resource Management, University of Edinburgh, Agriculture Building, West Mains Road, \\ King's Buildings, Edinburgh EH9 3JG, UK: ²Department of Economics, University of the Witwatersrand, 1 Jan Smuts \\ Avenue, Johannesburg, PO Box WITS 2050, South Africa: ${ }^{3}$ National Institute of Nutrition, Via Ardeatina 546, \\ 1-00178, Rome, Italy: ${ }^{4}$ Department of Child Life and Health, University of Edinburgh, Edinburgh EH9 3JG, UK: \\ ${ }^{5}$ Institute of Food, Nutrition, and Family Sciences, University of Zimbabwe, MP167 Mount Pleasant, Harare, \\ Zimbabwe
}

Submitted 18 October 1999: Accepted 21 September 2000

\begin{abstract}
Objective: To identify the season with the highest prevalence of underweight among young children and to examine geographical variation in seasonality of underweight. Design: This analysis is based on monthly data from a clinic-based growth monitoring programme that forms part of the National Health Information System. A regression-based technique is used to identify seasonal patterns in both underweight prevalence and attendance nationally and in 60 different districts. Setting: The analysis covers the period 1988-1995 and is based in Zimbabwe.

Subjects: The analysis is based on weight-for-age measurements of Zimbabwean children less than 5 years old, who attended health centres as part of a growth monitoring programme.

Results: Nationally, a small but significant increase in levels of underweight takes place during January-March. Participation in growth monitoring also varies seasonally and could account for the increase observed. No evidence of seasonal variation in underweight prevalence is found in the majority of districts studied, although 11 of the districts showed a similar pattern to the national data set. This peak in the incidence of poor nutritional status also coincides with the period of food scarcity before harvest, which is also associated with higher prevalence of diarrhoea and malaria. No differences in seasonality of under-nutrition were found between districts with predominantly subsistence agriculture and those with more commercial forms of agriculture.

Conclusions: Seasonal variation in child weight-for-age exists in some parts of Zimbabwe, but its effects on cross-sectional prevalence studies are likely to be small. There are no readily discernible differences between areas that show evidence of seasonality in levels of underweight and those that do not.
\end{abstract}

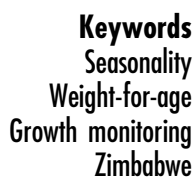

This paper reports on seasonal variation in levels of undernutrition in Zimbabwean infants and young children using nutritional surveillance data. Under-nutrition is defined as dietary intake below the minimum level for healthy growth and acceptable energy expenditure, and in this context is measured by the weight-for-age indicator.

The objectives of the study are to identify the extent of seasonal variation in under-nutrition across the whole country, to establish whether the same pattern of seasonality occurs in all parts of the country, and to identify possible reasons for the pattern observed. These objectives have several practical policy implications. First, better understanding of seasonal variation can aid the interpretation of cross-sectional prevalence surveys, particularly when comparing results from surveys that took place at different times of the year. Second, identification of seasonal patterns can guide the timing of appropriate interventions and provides an indication of the relative importance of the different causes of poor nutritional status.

In Zimbabwe, the three principal influences on children's nutritional status are regarded as household food security, health environment and services, and the level of care available within the household ${ }^{1}$. Of these, the most obvious cause of variation in child nutritional status is thought to occur through household food 
security. There are several types of agricultural production system in Zimbabwe and each has distinctive patterns of food security. The two largest systems are the large-scale commercial farming sector (comprising plantations and large, family-run farms on more productive land) and the Communal Areas, which lie in less productive land and comprise small-scale, predominantly subsistence farmers. Most agriculture is rain-fed with a single harvest per year, around April-May. In most years, households in at least some parts of the country are short of food between November and March. During this preharvest period, even subsistence communal farmers purchase the majority of staples through the marketplace $^{2}$. In terms of access to food for young children, this reliance on market purchases has two major implications. First, in poor communal households, increased spending on staples can reduce the amount of money available for purchasing nutrient-rich infant foods such as beans, milk, meat, and fruits if these are not produced by the household itself. Second, the need to work for income for food purchases can reduce the time available for child care, especially given that many communal household heads are women.

In the communal areas, adult men traditionally migrate in search of employment to other areas, so this means that women undertake agricultural work in addition to domestic chores and child care. Although exclusive breast-feeding is recommended up to the age of 4-6 months, at certain times of year, pressure on women's time may prevent such regular breast-feeding from taking place. One study of labour patterns in the Chivi communal area found peak agricultural activity occurring between October and March ${ }^{3}$. The most strenuous work took place during planting between October and November and harvesting between March and May, although poorer households also were also employed in weeding between these times. In the commercial farming sector women also form part of the workforce, although peak periods of labour vary across the country depending on the type of crops grown. As well as reducing the time available for child care ${ }^{4}$, high workloads for pregnant women can also directly affect the nutritional status of young children through the increased incidence of low birth-weight babies 5 .

Apart from changes in food consumption, nutritional status is also known to be closely related to health status, especially in younger children. Disease can reduce the body's ability to digest food and suppress appetite, leading to possible weight loss and retarded growth in children $^{6}$. In turn, poor nutritional status can reduce resistance to infection, leading to a 'malnutrition-infection complex'. In Zimbabwe, peaks in cases of the major childhood diseases occur in different seasons. The onset of the rains in October and November can wash faecal matter into unprotected water sources and contaminate supplies, resulting in increased incidence of diarrhoea in some areas ${ }^{1}$. Other major diseases show different prevalence patterns by season. Acute respiratory infections are more common during the colder winter months, whilst malaria peaks in March and April immediately after the rains, as the mosquito population flourishes.

Different stresses on nutritional status thus operate at different times of the year. The pre-harvest period is characterised by both increased diarrhoea prevalence and poorer food access, whilst during harvest malaria prevalence increases and labour demands are high. Over the winter months, respiratory infections are common despite improved food access. This paper investigates the season of greatest underweight prevalence to identify which of these stresses has the greatest impact on young children.

\section{Materials and methods}

\section{Subjects and data}

A growth monitoring programme has been operating in Zimbabwe since 1987, with nutritional assessment based on weight-for-age in children under 5 years old. The programme was established by the Nutrition Unit in the Ministry of Health as part of the National Health Information System (NHIS) ${ }^{7}$. One of the stated goals of the Government of Zimbabwe is the alleviation of malnutrition and the programme is intended to monitor the extent to which this has been achieved. The system monitors children under 5 years old, since this group is thought to be the most nutritionally vulnerable. Children are weighed at health centres or mobile field clinics, and those with weight-for-age below the third percentile of the NCHS reference population are classified as underweight. Each health centre or mobile clinic records details of children weighed on a tally sheet and, at the end of the month, passes this on to the main hospital for the district. These tally sheets are then either computerised at the district hospital or transferred to a summary sheet manually and sent to Harare for computerisation. In addition to the growth monitoring data, the number of cases of major childhood illnesses in children under 5 years old is also recorded. The system records cases of diarrhoea, acute respiratory infection and measles for example, but does not distinguish new cases from repeat visits. Monthly data from the NHIS were obtained for the period January 1988 to March 1993 and for January 1994 to December 1995 for 60 different Zimbabwean districts.

\section{Statistical analysis}

To reduce non-systematic errors, several consistency checks were performed on the growth monitoring data prior to analysis. First, a check was made to ensure that the number of children weighed was always greater than the number recorded malnourished for all age groups. Second, in cases where identical figures had been entered into the database for a district for two or more consecutive months, these were omitted from the analysis. Given the 
scope for data-entry, transcription or aggregation errors in the system, extreme values were also flagged and excluded from subsequent analysis. Such values were identified by calculating the inter-quartile range for each district and finding values that lay more than three interquartile ranges above or below the median. This flagging procedure follows that described elsewhere ${ }^{8}$, and was used both on the numbers of children who were weighed and on the percentage of children underweight. One per cent of the total number of monthly data points was flagged using this procedure.

Time series data (such as the monthly figures described here) often violate the assumptions of ordinary leastsquares regression because records for successive months are correlated with one another. The presence of this problem was identified by calculating the correlation between each month's underweight prevalence and that of the preceding month. Partial correlation coefficients were also calculated between current prevalence and prevalence two, three, four and five months previously, to identify how many of the preceding months' data were related to current prevalence. These partial correlation coefficients showed the strength of relationship between current and past underweight prevalence, having accounted for the effects of any intervening months.

Based on this analysis, a regression model was used to test for significant seasonal changes in underweight prevalence. Following a methodology used in econometrics 9 for identifying seasonal variability, a regression model of the following form was fitted, based on the method of maximum likelihood:

$$
\begin{aligned}
P_{t}= & s_{1} D_{1}+s_{2} D_{2}+s_{3} D_{3}+\sum_{I=1 \ldots n}\left(a_{(t-n)} P_{(t-n)}\right) \\
& +\sum_{I=1 \ldots n} \epsilon_{(t-n)}+c+\epsilon
\end{aligned}
$$

In this model, $P_{t}$ is underweight prevalence for month $t$, whilst the terms $D_{1}, D_{2}$ and $D_{3}$ represent the seasons January-March, April-June and July-September, respectively. Each of these variables took a value of one during the season concerned and a value of zero at all other times of the year. The fourth season, October-December, is represented by the constant term, $c$. The effect of past underweight prevalence on the current month's rate is modelled by the term $a_{(t-n)} p_{(t-n)}$, which represents the effect of prevalence $n$ months ago. The number of previous months included in the model $(n)$ varied from one to four, depending on the results of the correlational analysis described above. Furthermore, because of the problems of time series data for ordinary least-squares regression, the variability not explained by the model is represented by two error terms. The first term, $\boldsymbol{\epsilon}_{(t-n)}$, is the error that is related to underweight prevalence in previous months, whilst the second term, $\epsilon$, represents the remainder of the unexplained variation.

This technique was used to identify whether levels of under-nutrition increased significantly during any given season, both using prevalence data for each of the 60 districts and also nationally for all of the district data combined. In addition, a second model was tested against the national data, in which the number of cases of diarrhoea reported in the preceding month was also included as an explanatory variable. Regression results were then verified by inspecting changes in undernutrition prevalence over time graphically. Each district was classified according to the type of seasonality experienced and these classes were displayed using a Geographical Information System (GIS) to facilitate further interpretation. A GIS is a software program used to store maps and associated data in digital form. Once data are held in this manner, they become more amenable to investigation, manipulation and display as maps.

The regression-based test of seasonality was also performed on the number of children under 5 years old participating in the growth monitoring programme nationally. For this test, in calculating national figures by summing across the 60 districts, six districts were excluded because records of reported diarrhoea cases were incomplete. This test was used to identify seasonal variation in growth monitoring attendance, which might result in apparent seasonal changes in underweight prevalence.

\section{Results}

\section{District-level results}

The district-level regression analysis showed no significant seasonal change in the percentage of underweight children for the majority of districts. Amongst those that showed significant prevalence changes, seasonal variation was small. For such districts, underweight prevalence was highest during October-March and lowest between April and September. Within this overall pattern, four main types of seasonal change in percentage undernutrition were evident from the district-level analysis. Figure 1 shows the monthly change in percentage underweight by district for each of the four types of seasonal variation identified. Figure 2 shows the seasonal variation in percentage underweight for the four types of district and the spatial distribution of the four types is shown in Fig. 3. The characteristics of these types can be summarised as follows.

\section{Type A - no significant seasonal change in percentage under-nutrition}

This was the most common type identified, with 39 districts showing this pattern of seasonal change. Since numerous districts exhibited no significant seasonal change, for reasons of clarity Figs 1 and 2 show the pattern of variation for a sample of three of these districts only (Bulilimamangwe, Gwanda and Harare - see Fig. 3 for locations of districts referred to in the text). None of the coefficients for the three dummy variables $\left(s_{1}-s_{3}\right)$ 

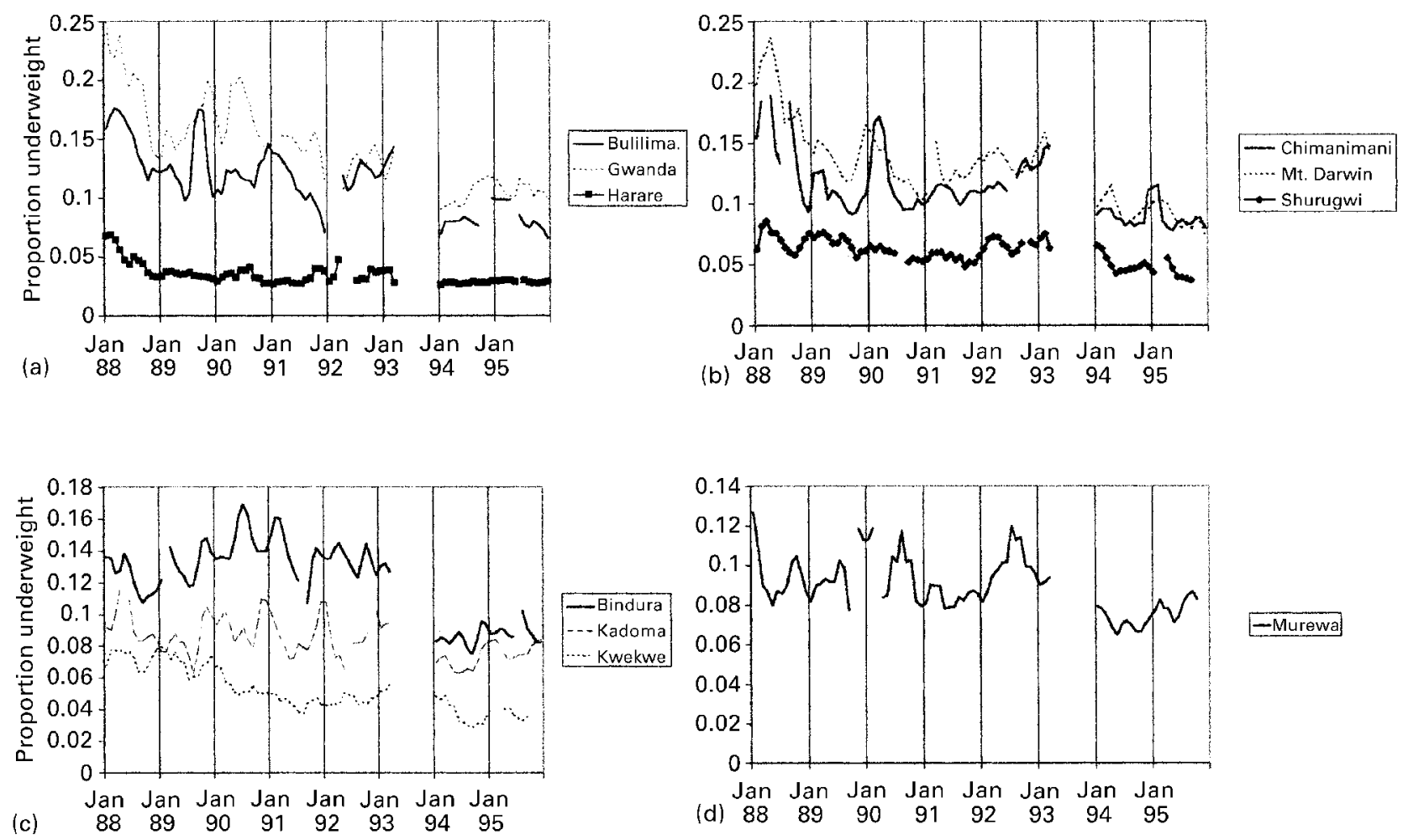

Fig. 1 Monthly changes in proportion of underweight children under five years old, 1988-1995, by district: (a) for three districts showing no seasonality (Type A); (b) for three districts showing a higher proportion of underweight children during January-March (Type B); (c) for three districts showing a lower proportion of underweight children during July-September (Type C); (d) for Murewa district, which showed a lower proportion of underweight children during April-June (Type D). Proportions shown are the centred moving average of three months' data

explained the observed pattern of under-nutrition, suggesting that there were no significant seasonal changes in weight-for-age malnutrition in children under 5 years old in these districts. In the case of Harare, for example, a significant relationship was identified only between the current month's underweight prevalence and that in the preceding month, but the seasonal variables were not significant. Although there is variability in percentage underweight, there is generally no consistency in the season of peak underweight from one year to the next. Thus, in Bulilimamangwe for example, the highest recorded underweight shown in Fig. 1(a) was around March in 1988, September in 1989, December in 1990 and January in 1991.

Type B - higher levels of under-nutrition in JanuaryMarch

Seven districts showed this type of seasonality and patterns are illustrated in Figs 1 and 2 for three of these districts (Chimanimani, Mount Darwin and Shurugwi). In Chimanimani district, for example, only the dummy variable for January-March proved significant in explaining underweight prevalence. The fitted regression model suggested that weight-for-age malnutrition averaged 10.6\% for April to December (as estimated by the constant, c), but increased significantly to $12.87 \%$ during
January to March (as estimated by the constant $c$ plus the seasonal dummy coefficient, $s_{1}$ ). The model also suggested that current levels of underweight were significantly related to levels one and two months previously (adjusted $R^{2}=0.34$ ). In Fig. 1(b), there is more consistency in the period with the peak proportion of underweight children than with Type A districts. For example, Mount Darwin shows higher percentage underweight in January-March in 1988, 1990, 1994 and 1995.

Type C - lower levels of under-nutrition during JulySeptember

Three districts (Kadoma, Kwekwe and Bindura) showed this type of seasonal pattern, as illustrated again in Figs 1 and 2 . In the case of Kadoma district, both the seasonal dummy variable for July-September and the coefficient for the previous month's underweight prevalence were significant in the regression model. The model suggested that the percentage of underweight children averaged 8.68\% for most of the year, but fell to $7.55 \%$ between April and June. As with Type B, this seasonal model explained little of the variability in percentage under-nutrition (adjusted $R^{2}=0.22$ ), suggesting that other factors also affected nutritional status during this period. 


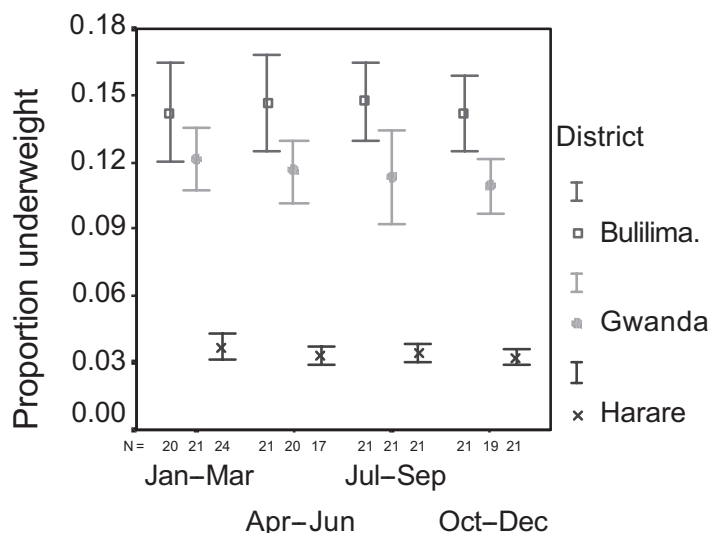

(a)

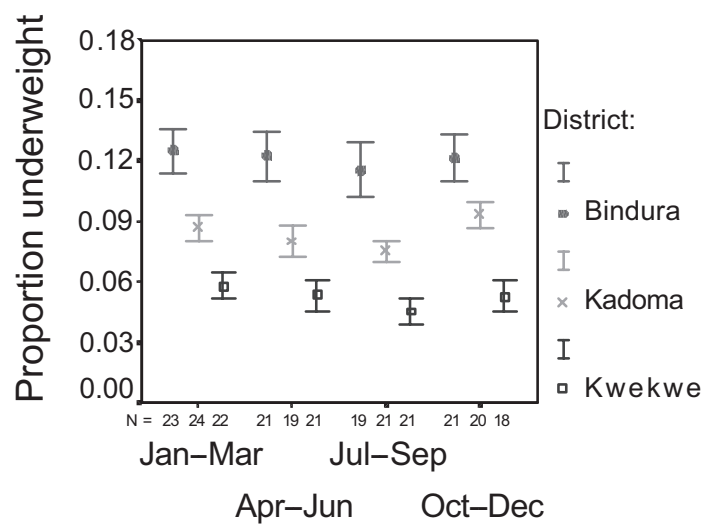

(c)

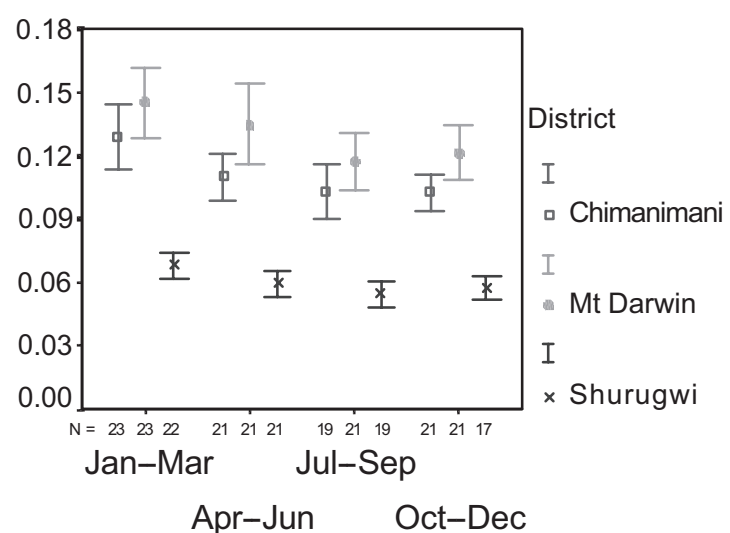

(b)

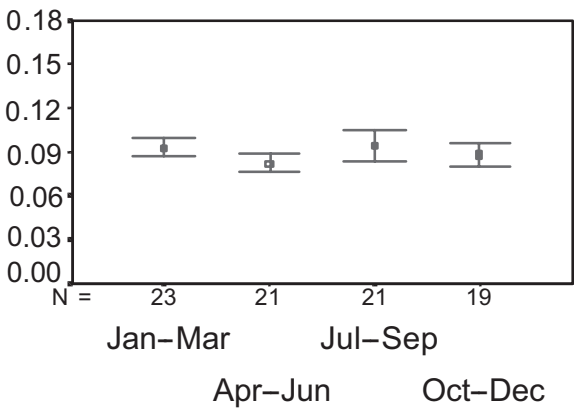

(d)

Fig. 2 Seasonal changes in proportion of underweight children under five years old, 1988-1995, by district: (a) for three districts showing no seasonality (Type A); (b) for three districts showing a higher proportion of underweight children during January-March (Type B); (c) for three districts showing a lower proportion of underweight children during July-September (Type C); (d) for Murewa district, which showed a lower proportion of underweight children during April-June (Type D). Error bars indicate 95\% confidence limits for seasonal mean

Type D - bigher levels of under-nutrition during AprilJune

This pattern of seasonal change occurred in only one district, Murewa. The fitted regression model included significant terms for underweight prevalence one and two months prior to the current month, as well as for the seasonal dummy variable for April-June (adjusted $\left.R^{2}=0.28\right)$. The model coefficients suggested a decrease in mean percentage under-nutrition from $9.02 \%$ for most of the year to $7.76 \%$ in April-June. As shown in Fig. 1(d), percentage underweight in Murewa was unusually high during April-June in 1990 and 1992.

\section{National-level results}

Nationally, the combined growth monitoring data for the whole country showed higher rates of underweight prevalence during January-March. Figure 4 shows the national trend in underweight prevalence over the study period, both by month and by season. In the regression analysis, the coefficients for underweight prevalence in the previous month and the January-March seasonal effect were both significant (adjusted $R^{2}=0.95$ ). The regression coefficients suggest an underweight prevalence of $10.74 \%$ for the April-December period (as estimated by the constant, c), rising significantly to $11.25 \%$ during January-March (as estimated by the constant $c$ plus the seasonal dummy coefficient, $s_{1}$ ). The coefficient for prevalence in the preceding month was highly significant, suggesting that the proportion of underweight children varied very little from one month to the next.

Analysis of the number of children weighed by month between 1988 and 1995 suggested that health centre attendance varied throughout the year, as shown both by month and by season in Fig. 5. This figure suggests little seasonal variation in participation in the weighing programme. This was confirmed by the regression analysis of national attendance, in which the seasonal dummy variable for April-June and the previous month's attendance figures were significantly associated with current attendance at the 99\% confidence level. The regression coefficients suggest that, on average, 33692 fewer children attended growth 


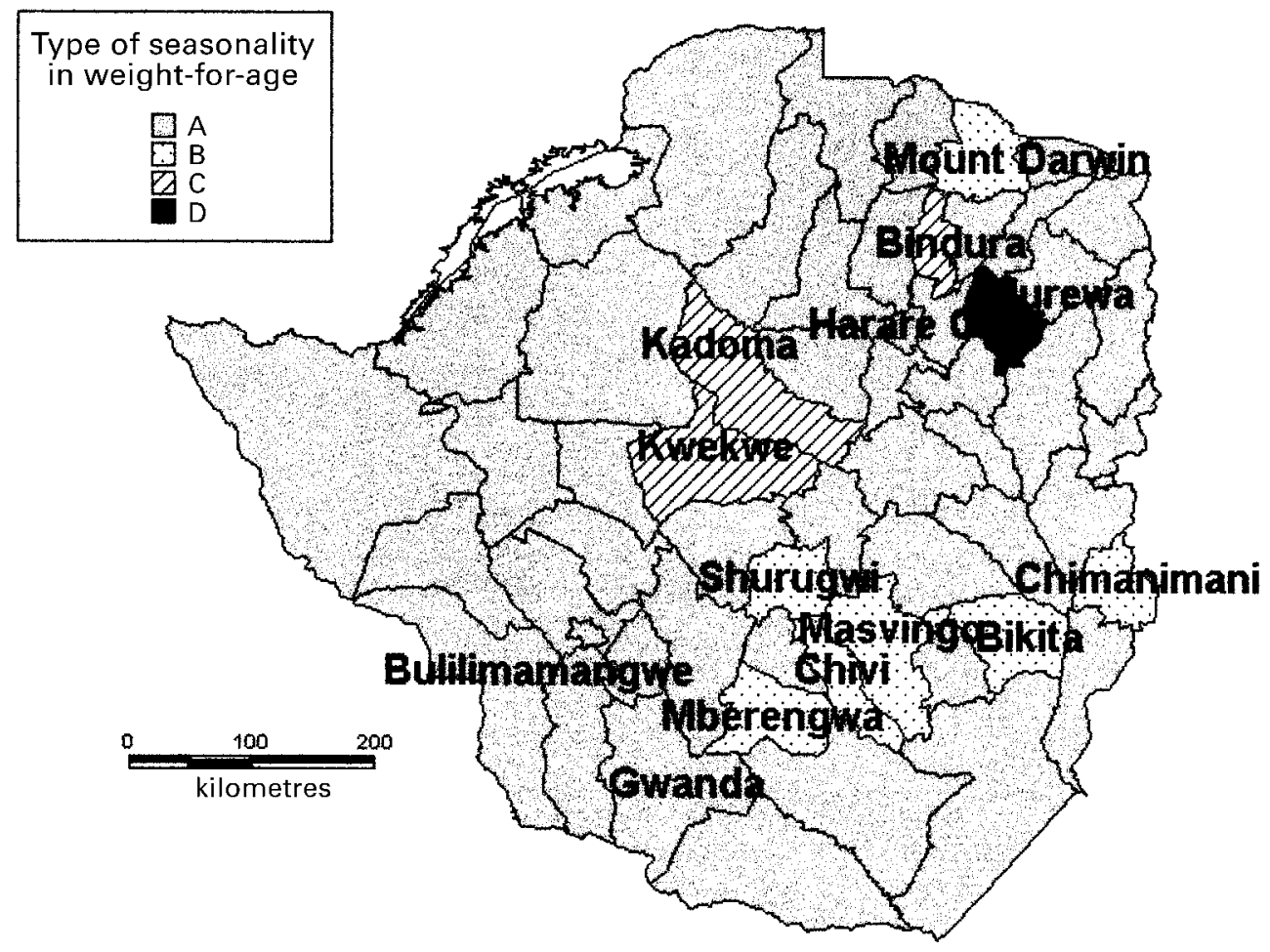

Fig. 3 Seasonal patterns of underweight prevalence in Zimbabwean districts (A - no significant seasonal changes; B - higher underweight prevalence during January-March; C - lower underweight prevalence during April-September; D - higher underweight prevalence during October-December). Source for map boundaries used: Africa Data Dissemination Service, US Geological Survey

monitoring during April-June. Overall, the regression model had an adjusted $R^{2}$ of 0.44 .

When the number of cases of diarrhoea reported through the NHIS was included in the national regression model, it was found to be significantly related to the proportion of underweight children. Coefficients for both the number of reported diarrhoea cases and underweight prevalence in the previous month were significant at the 99\% level, whilst the seasonal dummy variable for January-March was also significant in this model at the $95 \%$ level. The adjusted $R^{2}$ for this revised model was 0.82 .

\section{Discussion}

Previous work has suggested several different times of year for peak under-nutrition. Although some suggest the pre-harvest as the time of peak nutritional stress ${ }^{1}$, monthly data on child hospitalisation due to malnutrition in Gwanda District ${ }^{10}$ suggested that malnutrition was highest between October and November. Sixty per cent fewer cases related to malnutrition were reported in April compared with November. Elsewhere, at a district hospital in a large-scale commercial farming area, seasonal peaks in the number of hospital admissions due to malnutrition occurred from March to May and again from October to December ${ }^{11}$. The national results presented here suggest that, in contrast to the findings of these studies, the period before harvest in January-March is the time of greatest nutritional stress. This is apparent both from the regression results and from Fig. 4(a), which shows a higher proportion of underweight children during January-March for all years apart from 1992. In this year, the country was affected by severe drought in which production of the main crop, maize, fell to $21 \%$ of normal. It appears that, as a result of the exceptionally poor harvest in 1992, the usual post-harvest improvement in underweight amongst children did not occur.

This is further borne out by the number of districts experiencing higher rates of underweight between January and March or lower rates during winter. Given that 60 different districts were considered in this analysis, it was likely that at least some districts would have significant seasonal coefficients in the regression analysis by chance. However, almost a fifth of the districts (11) showed significant seasonal coefficients and furthermore, results for all of these districts consistently suggested higher underweight prevalence pre-harvest. These results are in keeping with those of an ad boc report on growth monitoring data ${ }^{12}$. This report suggested that the first or second quarters of the year were the times of greatest underweight prevalence for all but the 6-11-month-old cohort, based on a visual inspection of graphs of underweight prevalence. These findings are confirmed by the regression results presented here and the 


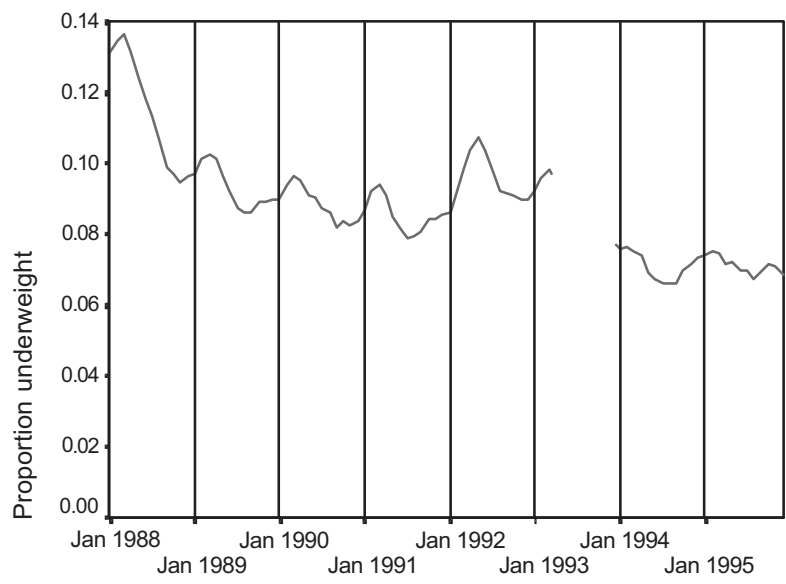

(a)

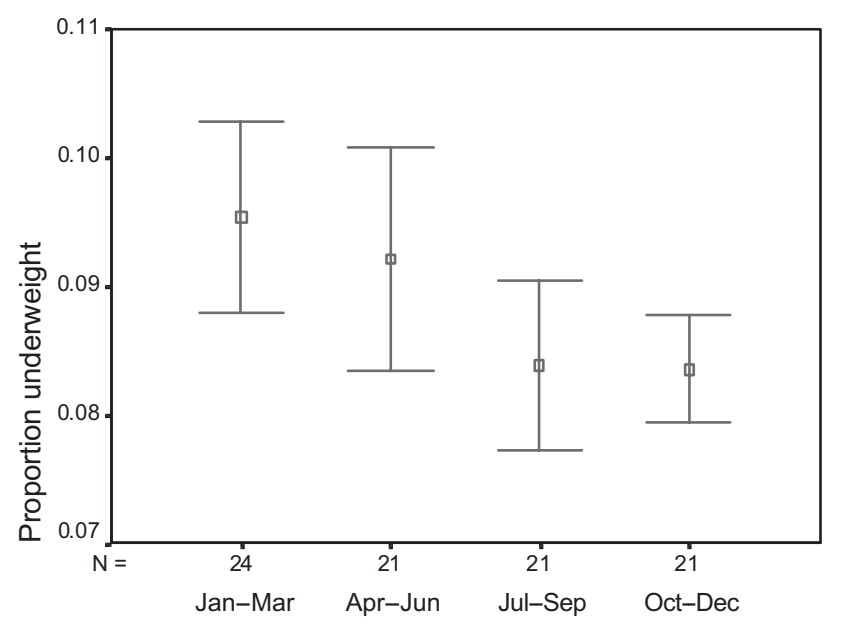

(b)

Fig. 4 National changes in proportion of underweight children under five years old, 1988-1995: (a) by month (rates shown are centred moving average of three months' data); (b) by season (error bars indicate $95 \%$ confidence limits for seasonal mean)

consistency of these results across many districts lends weight to this conclusion.

It should be noted that there are several limitations to the seasonality test used. First, the test distinguishes between four periods of three months: January-March, April-June, July-September and October-December. A change in the boundaries between these four periods (e.g. to FebruaryApril, May-July, etc.) could alter the results presented here. Similarly, the test does not assess monthly variability in underweight, which would be difficult to identify given the relative shortness of the time series.

Although the NHIS provides monthly growth monitoring data with nation-wide coverage, several problems make interpretation of these data difficult. Non-systematic errors, such as miscalibration of weighing scales, incorrect age assessment or transcription and data-entry errors, can occur $^{13}$. More importantly, the growth monitoring scheme includes only those who attend health centres for

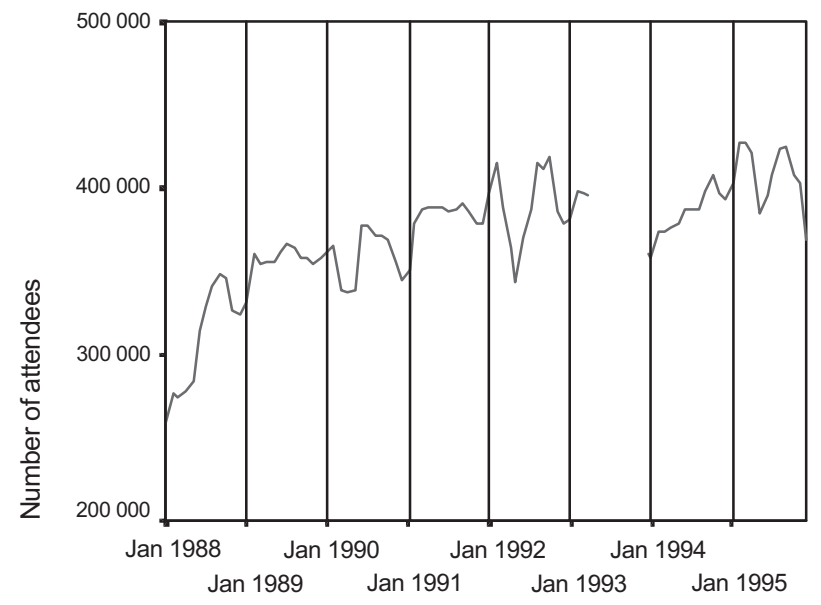

(a)

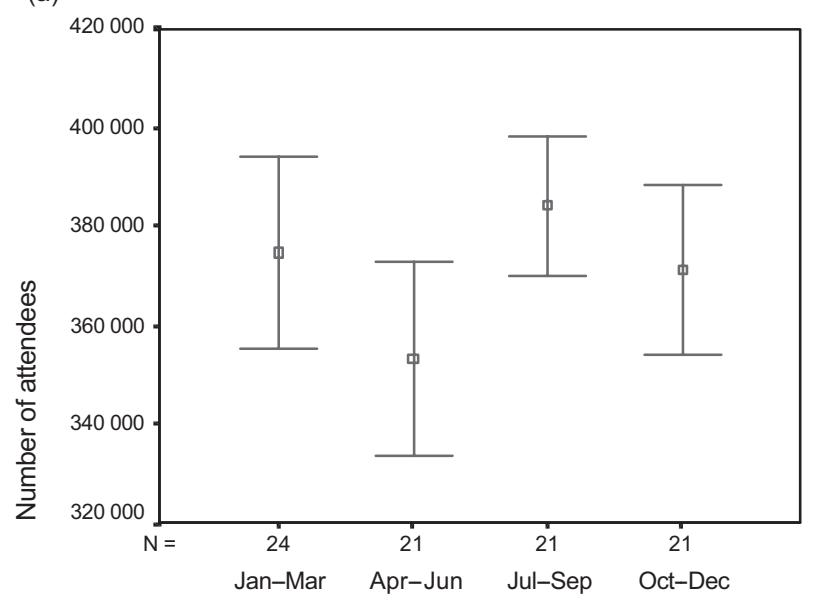

(b)

Fig. 5 Changes in total number of children under five years old participating in growth monitoring, 1988-1995: (a) by month; (b) by season (error bars indicate $95 \%$ confidence limits for seasonal mean)

weighing. If the nutritional status of these attendees differs from those who do not participate in the scheme, then this will result in systematic bias in the NHIS data. Since the number of attendees was significantly lower during April-June, it remains possible that the observed prevalence pattern could result from changes in the absolute number and characteristics of participants in growth monitoring. It is possible, for example, that underweight children are less likely to attend growth monitoring during April-June, compared with other times of the year, thus explaining the observed seasonal variability in percentage underweight.

Although changes in the number and characteristics of growth monitoring participants may explain seasonal variability in underweight, the observed changes in underweight may also be a consequence of the stresses during January-March noted earlier. These include higher diarrhoea prevalence in this period, poorer food access as household budgets are dominated by market purchases of 
staples, and increased workloads for rural women during weeding and harvest reducing time for child care. When reported diarrhoea cases were included in the national regression analysis, both this disease-related variable and the seasonal effect for January-March were significant. This implies that other seasonal factors (food shortage, reduced time for child care) are operating during January-March in addition to the increase in reported diarrhoea cases. Stresses at other times of year (such as the rise in acute respiratory infections over winter, the rise in cases of malaria at the end of the wet season in AprilMay, and demands on women's time during planting) appear to have less of an impact on child nutritional status.

Figure 3 suggests an absence of seasonality in the major cities of Harare, Bulawayo and Mutare. There is a greater tendency towards seasonality in the eastern part of the country and Type B districts are concentrated in Masvingo Province, but, other than this, the districts showing seasonality do not appear to share any common characteristics. It has been suggested that the magnitude of seasonal change in nutritional status varies geographically within Zimbabwe. A longitudinal sample survey of farm workers' children under 30 months old in Shamva District suggested that there was no seasonal trend in growth $^{14}$. These authors suggested that seasonal food shortages did not occur in such commercial farming environments, since employment and earnings were constant throughout the year. This argument would also account for the absence of seasonality in the major cities in this study. However, several of the districts with Type B or C seasonality lie in predominantly commercial farming areas (notably Kadoma, Kwekwe, Bindura and Shurugwi). Thus, despite earlier work in commercial farming areas, there is no evidence in the growth monitoring data that children on commercial farms have been less prone to seasonal nutritional stress.

These results have several policy implications. First, several cross-sectional studies have assessed underweight prevalence in young Zimbabwean children using anthropometry. These surveys have included in particular the Demographic and Health Surveys of September 1988January 1989 and July-November 1994. In interpreting the results of these surveys and comparing prevalence at different times, the effect of seasonal variability on prevalence estimates needs to be identified. The results presented here suggest that seasonal influences on the prevalence estimates from these surveys are small and unlikely to substantially affect estimation of underweight trends. Second, on the basis of past experience, health services can expect to encounter slightly more cases of underweight during January-March and sudden increases in underweight are unlikely. Geographically, this seasonal trend in underweight is just as common in commercial farming areas as in the subsistence-based communal lands, although no such pattern was observed in the major cities. Third, the results suggest that the effect on underweight prevalence of higher levels of respiratory infection over the drier, colder months is less than that of factors such as food scarcity and greater levels of diarrhoea between January and March.

\section{Acknowledgements}

The authors would like to thank staff at the Ministry of Health and Child Welfare for their assistance in preparing the growth monitoring data, and Gary Eilerts and Jo Dooley of USAID and the Department of Social Welfare for their help with the preparation of the 1988-1993 health data set. The authors are also grateful to Professor OW Heal for his comments on this work. This work was funded by the European Union, Science and Technology for Developing Countries Programme, Contract Ref. TS3 ${ }^{*}-\mathrm{Ct} 92-0048$.

\section{References}

1 Tagwireyi J, Greiner B. Nutrition in Zimbabwe: An Update. Washington, DC: World Bank, 1994.

2 Corbett J. Livelihoods, Food Security, and Nutrition in a Drought-prone Part of Zimbabwe. ESCOR Report No. R4685. Oxford: University of Oxford, 1994.

3 IIED/FSRU. Coping with Uncertainty in Africa's Drylands. Final Technical Report submitted to the European Community. London: Drylands Programme, IIED, 1994.

4 Wandel M, Holmboeottesen G, Manu A. Seasonal work, energy-intake and nutritional stress - a case study from Tanzania. Nutr. Res. 1992; 12(1): 1-16.

5 Andren G, Jacobson T. Birthweights in Mashonaland East and Greater Harare. Department of Statistics Working Paper. Uppsala, Sweden: University of Uppsala, 1986.

6 Tomkins A, Watson F. Malnutrition and Infection: A Review. Lavenham, Suffolk: The Lavenham Press Ltd, 1989.

7 Lenneiye, NM. Towards a food and nutrition policy for Zimbabwe. In: UZ/MSU Food Security Project, ed. Towards an Integrated National Food Policy Strategy. Proceedings of the Second National Consultative Workshop on Integrating Food, Nutrition, and Agricultural Policy, Troutbeck Inn, Nyanga, 10-12 June. Harare: Sebi Printers, 1991; 51-95.

8 Haining R. Spatial Data Analysis in the Social and Environmental Sciences. Cambridge: Cambridge University Press, 1990.

9 Gujarati DN. Basic Econometrics. 2nd ed. London: McGrawHill, 1988.

10 World Bank. Zimbabwe Population, Health and Nutrition Sector Review: Vol. 2. Washington, DC: World Bank, 1983.

11 Loewenson R. Modern Plantation Agriculture: Corporate Wealth and Labour Squalor. London: Zed Books Ltd, 1992.

12 Government of Zimbabwe. Trend Analysis of the Weight-forage Indicator of Malnutrition 1988-1993. Harare: Ministry of Health and Child Welfare, 1994.

13 Ruel MT. Growth monitoring as an educational tool, an integrating strategy, and a source of information: a review of experience. In: Pinstrup-Anderson P, Pelletier D, Alderman H, eds. Child Growth and Nutrition in Developing Countries: Priorities for Action. London: Cornell University Press, 1995; 78-96.

14 Moy RJD, Booth IW, Choto R, McNeish AS. Early growth faltering in rural Zimbabwean children. Central African J. Med. 1991; 37(9): 275-82 